joint." It is of considerable interest that this patient developed an articular erosion in the carpal bones of the left hand, which has subsequently healed.

In conclusion, Mycoplasma pneumoniae infection may cause arthralgias or myalgias. Less commonly it may cause a migratory polyarthropathy affecting middle-sized joints. This condition may be severe, with joint swelling, morning stiffness, gelling, and considerable functional disability, and it may be the dominant clinical feature outlasting all other mainfestations of the disease, though remission can usually be expected within eight weeks.

Rarely a peripheral symmetrical polycarthritis indistinguishable from rheumatoid arthritis may occur. There may be synovial hypertrophy with a high articular index, and articular erosions or rheumatoid factor may be present. The overlying skin may be red and inflamed, which is not the case in uncomplicated rheumatoid arthritis. Serum complement concentrations may fall, but in our patient in whom this occurred all abnormalities reverted to normal and she was well two years later. In the two patients who developed polyarthritis resembling rheumatoid arthritis increases in Mycoplasma pneumoniae antibody titres were documented and there seems no reason to doubt that their illness was caused by mycoplasma arthritis. Clearly man can suffer mycoplasma infections and may respond with a clinical and laboratory picture very like that of classical rheumatoid arthritis. The most appropriate description of the illness suffered by these patients seems to be "reactive arthritis," and the prognosis seems to be favourable though the illness may be severe and prolonged. It would seem best to avoid the use of potentially toxic drug regimens in such patients.

Requests for reprints should be addressed to Dr W Carson Dick, Centre for Rheumatic Diseases, 35 Baird Street, Glasgow G4 0EH.

\section{References}

1 Sharp, J T, and Riggs, S, Rheumatism, 1976, 1, 51

2 Sharp, J T, Arthritis and Rheumatism, 1970, 13, 263.

${ }^{3}$ Sabin, A B, and Warren, J, fournal of Bacteriology, 1940, 40, 823.

4 Jansson, E, Makisara, P, and Tuuri, S, Scandinavian fournal of Rheumatology, 1975, 4, 165 .

${ }^{5}$ Mufson, M A, et al, fournal of the American Medical Association, 1961, 178, 369.

${ }^{6}$ George, R B, et al, Annals of Internal Medicine, 1966, 65, 931.

7 Feizi, T, et al, British Medical fournal, 1967, 1, 457.

${ }^{8}$ Lambert, H P, British Medical fournal, .1968, 3, 156.

9 Jones, M C, Thorax, 1970, 25, 748.

10 Murray, H W, et al, American fournal of Medicine, 1975, 58, 229.

11 Ritchie, D M, et al, Quarterly fournal of Medicine, 1968, 37, 393.

12 Aho, K, et al, Arthritis and Rheumatism, 1974, 17, 521.

13 Girwood, R H, British Medical fournal, 1974, 1, 501.

14 Boyle, J A, and Buchanan, W W, Glinical Rheumatology. Edinburgh, Blackwell Scientific, 1971.

(Accepted 22 April 1977)

\title{
Spontaneous premature birth in twin pregnancy
}

\author{
A R L WEEKES, D N MENZIES, C R WEST
}

British Medical fournal, 1977, 2, 16-18

\section{Summary}

Factors associated with spontaneous premature birth were investigated in 459 consecutive twin deliveries at this hospital. Low maternal age, low parity, and zygosity were significantly related to the incidence of this complication. The number of previous abortions, sex combinations and related birth order, and mode of presentation of the first twin were not related to the incidence of spontaneous premature delivery. We conclude that apart from low maternal age and low parity there are no obvious factors that would permit early identification of twin pregnancies at risk from spontaneous premature birth.

\section{Introduction}

Spontaneous premature birth is the main reason for the high perinatal mortality in twin pregnancy. ${ }^{12}$ Since there are no

Liverpool Maternity Hospital, Liverpool L7 3BN

A R L WEEKES, FRCS, MRCOG, senior registrar

D N MENZIES, FRCS, FRCOG, consultant obstetrician and gynaecologist

Biostatistics Unit, University of Liverpool, Liverpool L69 3 B5

C R WEST, MA, statistical assistant satisfactory criteria for identifying twins at particular risk from premature birth, we decided to see whether there are any readily identifiable clinical features associated with spontaneous premature birth in twin pregnancy.

\section{Patients and methods}

We reviewed the obstetric records of the 459 twin pregnancies documented at this hospital during 1964-73. Seventy-five patients were excluded from the final analysis because they aborted, required induction of labour for pregnancy complications, or were delivered by elective caesarean section. Of the remaining 384 patients, $95(24.7 \%)$ went into spontaneous labour before the 36th week of gestation (premature delivery), and in $289(75.3 \%)$ pregnancy continued until or beyond the 36th week. We compared the two groups with respect to maternal age, numbers of previous abortions, parity, zygosity and sex combinations of the twins, and mode of presentation of the first-born. Zygosity had been determined macroscopically, the generally accepted principles for examination of twin placentae being used. ${ }^{3}$

The significance of differences between the two groups was assessed with the $\chi^{2}$ test. Partial correlation coefficient analysis was used to check that the results relating to maternal age were independent of parity. Weinberg's $\mathrm{s}^{4}$ differential method of estimating the proportion of monozygotic pairs to be expected in a given sample of twins was applied to verify the findings related to zygosity.

\section{Results}

There was a significant association between low maternal age and premature birth (table I; $\mathbf{P}=0.0037$ ) particularly for age 20 or less $(P=0.000096)$. This association was independent of parity (partial 
correlation coefficient between gestational age and maternal age holding parity constant: $\mathrm{r}=+0.111 ; \mathrm{P}=0.031$ ).

TABLE I-Distribution by age of mothers delivered before 36 weeks and at 36 weeks or later

\begin{tabular}{c|c|c|c|c|c|c}
\hline & \multicolumn{3}{|c|}{ Age in years } & & \multirow{2}{*}{ Total } \\
\cline { 2 - 5 } & $\leqslant 20$ & $21-$ & $26-$ & $31-$ & 36 & \\
\hline No delivered before 36 weeks.. & 16 & 31 & 24 & 20 & 4 & 95 \\
\hline No delivered 36 weeks or later .. & 12 & 89 & 105 & 54 & 29 & 289 \\
\hline Total & 28 & 120 & 129 & 74 & 33 & 384 \\
\hline
\end{tabular}

$\varkappa^{2}$ for trend: $8 \cdot 41 ; \mathrm{DF}=1 ; \mathrm{P}=0.0037$.
$\mathrm{Age} \leqslant 20 v$ age $: 21: \%^{2}=15 \cdot 21 ; \mathrm{DF}=1 ; \mathrm{P}=0.000096$.

There was no significant association between the number of previous abortions and spontaneous premature birth (table II $; P=0.92$ ). There was, however, a significant reduction in premature births with increasing parity (table III; $\mathrm{P}=0.026$ ).

TABLE II-Numbers of previous abortions among mothers delivered before 36 weeks and at 36 weeks or later

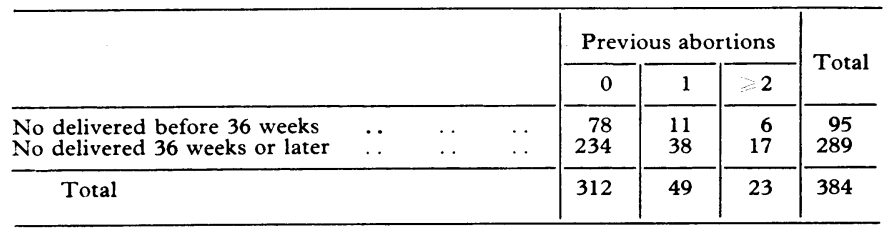

$\chi^{2}=0 \cdot 172 ; \mathrm{DF}=2 ; \mathrm{P}=0.92$

TABLE III-Numbers of previous viable pregnancies among mothers delivered before 36 weeks and at 36 weeks or later

\begin{tabular}{cl|r|r|r|r|r|r}
\hline & \multicolumn{3}{|c|}{ Previous viable pregnancies } & \multirow{2}{*}{ Total } \\
\cline { 2 - 5 } & 0 & 1 & 2 & 3 & $\geqslant 4$ & \\
\hline $\begin{array}{c}\text { No delivered before 36 weeks } \\
\text { No delivered 36 weeks or later }\end{array}$ &. & 32 & 41 & 10 & 9 & 3 & 95 \\
\hline Total & & 92 & 58 & 33 & 22 & 289 \\
\hline
\end{tabular}

$\chi^{2}$ for trend: $4.97 ; D F=1 ; P=0.026$.

A significantly higher proportion of monozygotic twins was delivered before 36 weeks than dizygotic twins (table IV; $P=0.001$ ). In contrast, similar proportions of dizygotic pairs of like and unlike sex were delivered before 36 weeks (table $\mathrm{V} ; \mathrm{P}=0.671$ ).

Sex combinations and associated birth order were not significantly related to spontaneous premature birth (table VI; $P>0.1$ in all cases). Likewise, the incidence of premature delivery was similar regardless of whether the first twin presented by the head or the breech (table VII; P $>0 \cdot 1$ ). Five patients $(1 \cdot 3 \%$ ) had clinically

TABLE IV-Zygosity of twins delivered before 36 weeks and at 36 weeks or later

\begin{tabular}{c|c|c|c|c|c|c}
\hline \multirow{2}{*}{$\begin{array}{c}\text { Gestational } \\
\text { age (weeks) }\end{array}$} & \multicolumn{2}{|c|}{ Monozygotic } & \multicolumn{2}{|c|}{ Dizygotic } & \multicolumn{2}{|c}{ Total } \\
\cline { 2 - 6 } & No & EF & No & EF & No & EF \\
\hline $\begin{array}{c}<36 \\
36\end{array}$ & 36 & 40 & 59 & 55 & 95 & 95 \\
\hline Total & 59 & 75 & 230 & 214 & 289 & 289 \\
\hline & 95 & 115 & 289 & 269 & 384 & 384 \\
\hline
\end{tabular}

$\mathrm{EF}=$ Estimated frequency assessed according to Weinberg's rule.
Monozygotic $v$ dizygotic twins: $\chi^{2}=10 \cdot 81 ; \mathrm{DF}=1 ; \mathrm{P}=0.001$. diagnosed polyhydramnios; of these, four were delivered before 36 weeks. Among the 384 sets of twins the perinatal mortality (excluding major congenital abnormalities) was $6.8 \%$

TABLE $\mathrm{v}-$ Unlikeness and likeness of sex of dizygotic twins delivered before 36 weeks and at 36 weeks or later

\begin{tabular}{c|c|c|c}
\hline $\begin{array}{c}\text { Gestational age } \\
\text { (weeks) }\end{array}$ & No unlike & No like & Total \\
\hline$<36$ & 25 & 34 & 59 \\
$>36$ & 107 & 123 & 230 \\
\hline Total & 132 & 157 & 289 \\
\hline
\end{tabular}

Unlike $v$ like twins: $\varkappa^{2}=0.179 \mathrm{DF}=1 ; \mathrm{P}=0.671$.

TABLE VI-Sex combinations and birth order of twins delivered before 36 weeks and at 36 weeks or later

\begin{tabular}{|c|c|c|c|c|c|}
\hline \multirow{2}{*}{$\begin{array}{l}\text { Gestational } \\
\text { age (weeks) }\end{array}$} & \multicolumn{4}{|c|}{ Sex of twins 1 and 2} & \multirow{2}{*}{ Total } \\
\hline & $\begin{array}{l}1 \mathrm{M} \\
2 \mathrm{M}\end{array}$ & $\begin{array}{l}1 \mathrm{M} \\
2 \mathrm{~F}\end{array}$ & $\frac{1 \mathrm{~F}}{2 \mathrm{M}}$ & ${ }_{2 F}^{1 F}$ & \\
\hline $\begin{array}{l}<36 \\
\geqslant 36\end{array}$ & $\begin{array}{r}40 \\
101\end{array}$ & $\begin{array}{l}16 \\
55\end{array}$ & $\begin{array}{r}9 \\
53\end{array}$ & $\begin{array}{l}30 \\
80\end{array}$ & $\begin{array}{r}95 \\
289\end{array}$ \\
\hline Total & 141 & 71 & 62 & 110 & 384 \\
\hline
\end{tabular}

$\chi^{2}=5 \cdot 042 ; \mathrm{DF}=3 ; \mathrm{P}=0 \cdot 17$ (not significant).

TABLE VII-Modes of presentation of first twin in deliveries before 36 weeks and 36 weeks or later (14 cases with unusual presentations were excluded)

\begin{tabular}{c|c|c|c}
\hline $\begin{array}{c}\text { Gestational } \\
\text { age (weeks) }\end{array}$ & $\begin{array}{c}\text { Head } \\
\text { presentation }\end{array}$ & $\begin{array}{c}\text { Breech } \\
\text { presentation }\end{array}$ & Total \\
\hline $\begin{array}{c}<6 \\
\sum 36\end{array}$ & 228 & 21 & 93 \\
\hline Total & 300 & 49 & 277 \\
\hline
\end{tabular}

$\chi^{2}=0.79 ; \mathrm{DF}=1 ; \mathrm{P}=0.37$ (not significant)

\section{Discussion}

These results show a significant association between spontaneous premature birth and maternal age, parity, and zygosity. Polyhydramnios might also be associated with an increased risk of premature birth, but there were too few patients with this complication for any definite conclusions to be drawn.

Monozygous twins are clearly at greater risk than dizygous twins. In contrast, similar proportions of dizygous twins of like and unlike sex were born prematurely. Low maternal age carries a substantial risk of spontaneous premature birth; at greatest risk was the mother aged 20 or less. Increasing parity, however, was associated with a significant reduction in the trend to deliver prematurely. This is in contrast to a report on singleton pregnancies, in which parity was not found to be related to premature birth. ${ }^{5}$ Our findings related to age, low parity, and zygosity corroborate the higher perinatal mortality rate found previously to be associated with these factors. ${ }^{6}$

Our results do not support the claim that the mode of presentation of the first twin influences the incidence of spontaneous premature birth in twin pregnancy. ${ }^{7} \mathrm{~A}$ higher perinatal mortality has been reported in male-male combinations and in mixed-sex twins when the second twin was male. ${ }^{7} \mathrm{We}$ found no evidence to suggest that this is related to spontaneous premature birth, as the premature birth rates were similar regardless of sex combination and associated birth order.

We conclude that apart from maternal age, low parity, and possibly polyhydramnios there are no easily recognisable features that would identify twin pregnancies at risk from spontaneous premature birth. 
We thank the consultant obstetricians at the Liverpool Maternity Hospital who allowed us to study patients under their care.

\section{References} \\ 1 Anderson, W J R, fournal of Obstetrics and Gynaecology of the British \\ Empire, 1956, 63, 205. \\ 2 Seski, A G, and Millar, L A, Obstetrics and Gynaecology, 1963, 22, 227.
}

${ }^{3}$ Benirschke, K, Obstetrics and Gynecology, 1961, 18, 334.

${ }^{4}$ Weinberg, W, Pflügers Archiv für die gesamte Physiologie, 1902, 88, 346.

${ }^{5}$ Fredrick, J, and Anderson, A B M, British fournal of Obstetrics and Gynaecology, 1976, 83, 342.

${ }^{6}$ Butler, N R, and Alberman, E D, editors, in Perinatal Problems: Perinatal Mortality Survey, p 140. Edinburgh, Livingstone, 1969.

' Barter, R, American fournal of Obstetrics and Gynecology, 1963, 91, 784.

${ }^{8}$ Lowe, C R, and Record, R G, British fournal of Sociological Medicine, $1951,5,34$.

(Accepted 22 April 1977)

\title{
Mood changes in puerperium, and plasma tryptophan and cortisol concentrations
}

\author{
S L HANDLEY, T L DUNN, J M BAKER, C COCKSHOTT, S GOULD
}

British Medical fournal, 1977, 2, 18-22

\begin{abstract}
Summary
Eighteen women aged 18-31 years were studied daily during the second to fifth postpartum days to assess mood changes and plasma tryptophan and cortisol concentrations. Psychiatric rating scales, clinical interviews; and published biochemical methods were used. Over the period plasma free tryptophan concentrations tended to rise and plasma cortisol concentrations to decline. There was a positive correlation between plasma free tryptophan concentrations and mood state.
\end{abstract}

\section{Introduction}

Puerperal depression has received increasing attention during the past few years, and Yalom et al estimated that up to $70 \%$ of mothers have the "four-day blues." upsets occur at a time of profound biochemical changes, the puerperium may be an appropriate model for investigating possible links between biochemistry and affect. Depressive illness may be related to a functional deficiency of 5-hydroxytryptamine $(5-\mathrm{HT}) .{ }^{2-4}$ The rate of brain $5-\mathrm{HT}$ synthesis may depend at least in part on the concentration of tryptophan in the plasma, ${ }^{5}$ particularly the fraction not bound to albumin. ${ }^{6}$ Plasma free tryptophan concentrations, however, may be lowered, ? raised, ${ }^{8}$ or unchanged ${ }^{9}$ in depressive illness. Stein et al recently found that on day 6 post partum free plasma tryptophan concentrations were significantly reduced in patients with the most severe depression. ${ }^{10}$

Cortisol, on the other hand, may be increased during depressive illness. ${ }^{11-13}$ During the early puerperium this hormone declines rapidly from the peak concentrations attained

University of Aston, Birmingham B4 7ET

S L HANDLEY, BPHARM, PHD, lecturer in pharmacology

J M BAKER, BSP, PHD, research fellow

S GOULD, BSC, MPS, research assistant

Walsgrave Hospital, Coventry CV2 2DX, and Central Hospital, Warwick CV35 7EE

T L DUNN, FRCPSYCH, FRCPGLAS, consultant psychiatrist

C COCKSHOTT, MB, CHB, part-time registrar in psychiatry during labour. ${ }^{14}$ Moreover, cortisol can affect the availability of brain 5 -HT in several ways. ${ }^{15} 16$

In this preliminary study we examined the relation between plasma cortisol concentrations, free and bound tryptophan concentrations, and emotional state during the days immediately after childbirth to try to clarify the means by which mood changes occur in the puerperium.

\section{Patients and methods}

Over a four-week period women presenting to the maternity unit were considered for the study provided they were UK-born, aged 18-31 years, had given birth to live infants, and were willing to cooperate. Eighteen women fulfilled these criteria and were accepted serially. A standard, low-protein breakfast was given each morning, and drugs known to interfere with tryptophan binding were avoided. ${ }^{17}$ Samples of venous blood $(10 \mathrm{ml})$ were obtained daily between 0900 and 0930 and the plasma was analysed for cortisol, total tryptophan, and free tryptophan according to published methods. ${ }^{18-21}$ The patients were studied during the second to fifth "obstetric days," the day of parturition being regarded as day 0 if birth occurred after 1200 and as day 1 if it occurred before 1200 .

Three self-rating scales were used for quantitative psychiatric assessment. These were administered immediately after blood sampling. The Multiple Affect Adjective Check List (MAACL), ${ }^{22}$ which includes scales for depression, anxiety, and hostility, was used daily. The Beck Depression Inventory ${ }^{23}$ with the modification of Pichot $e t a l^{24}$ was also used to detect depression, and the Hildreth Feeling Scale ${ }^{25}$ to detect elation or mania, or both. These last two scales were used twice. A brief clinical interview was carried out each day on completion of the rating scales. The study was blind in that the biochemical results were unknown to the clinician performing the psychiatric assessment, and the scores for the rating scales were not computed until the end of the study.

\section{Results}

The table shows the mean biochemical values for the 18 women. Plasma cortisol steadily declined over the period, whereas the total plasma tryptophan concentration tended to rise, as did the percentage of free tryptophan. Consequently the absolute concentration of free tryptophan also rose.

None of the women was diagnosed as suffering from depressive illness at clinical interview. Three, however, exhibited elevation of mood throughout their stay, but this was not judged by the interviewer to be clinical hypomania. The figure shows the mean scores obtained on the psychiatric rating scales each day. Data for the three women showing consistent elevation of mood are plotted separately and show that for these women the Beck-Pichot scores were zero throughout. 